\title{
Calcium-dependent inhibition of T-type calcium channels by TRPV1 activation in rat sensory neurons
}

\author{
Valentina Comunanza • Emilio Carbone • \\ Andrea Marcantoni · Emanuele Sher • Daniel Ursu
}

Received: 28 July 2011 /Revised: 23 August 2011 / Accepted: 24 August 2011 /Published online: 9 September 2011

(C) Springer-Verlag 2011

\begin{abstract}
We studied the inhibitory effects of transient receptor potential vanilloid-1 (TRPV1) activation by capsaicin on low-voltage-activated (LVA, T-type) $\mathrm{Ca}^{2+}$ channel and highvoltage-activated (HVA; L, N, P/Q, R) currents in rat DRG sensory neurons, as a potential mechanism underlying capsaicin-induced analgesia. T-type and HVA currents were elicited in whole-cell clamped DRG neurons using ramp commands applied before and after 30-s exposures to $1 \mu \mathrm{M}$ capsaicin. T-type currents were estimated at the first peak of the $I-V$ characteristics and HVA at the second peak, occurring at more positive potentials. Small and medium-sized DRG neurons responded to capsaicin producing transient inward currents of variable amplitudes, mainly carried by $\mathrm{Ca}^{2+}$. In those cells responding to capsaicin with a large $\mathrm{Ca}^{2+}$ influx (59\% of the total), a marked inhibition of both T-type and HVA $\mathrm{Ca}^{2+}$ currents was observed. The percentage of T-type and HVA channel inhibition was prevented by replacing $\mathrm{Ca}^{2+}$ with $\mathrm{Ba}^{2+}$ during capsaicin application or applying high doses of intracellular BAPTA $(20 \mathrm{mM})$, suggesting that TRPV1mediated inhibition of T-type and HVA channels is $\mathrm{Ca}^{2+}$ dependent and likely confined to membrane nanomicrodomains. Our data are consistent with the idea that TRPV1-induced analgesia may derive from indirect inhibition of both T-type and HVA channels which, in turn, would reduce the threshold of nociceptive signals generation (T-type channel inhibition) and nociceptive synaptic transmission (HVA-channels inhibition).
\end{abstract}

V. Comunanza $\cdot$ E. Carbone $\cdot$ A. Marcantoni

Department of Neuroscience, NIS Center, CNISM Research Unit,

10125 Torino, Italy

E. Sher $\cdot$ D. Ursu $(\bowtie)$

Lilly Research Centre, Eli Lilly and Company,

Windlesham, Surrey GU20 6PH, UK

e-mail: ursu_daniel@lilly.com
Keywords TRPV1 Capsaicin - T-type Cav3.2 channels . Nociceptive DRG neurons

\section{Introduction}

Voltage-dependent $\mathrm{Ca}^{2+}$ channels represent crucial $\mathrm{Ca}^{2+}$ entry paths into excitable cells. They are classified as highvoltage-activated (HVA, that include $\mathrm{L}, \mathrm{N}, \mathrm{P} / \mathrm{Q}$ and $\mathrm{R}$ types) and low-voltage-activated (LVA, T-type) $\mathrm{Ca}^{2+}$ channels. T-type $\mathrm{Ca}^{2+}$ channels are transient channels that control $\mathrm{Ca}^{2+}$ entry during mild depolarizations around the resting potential. T-type channels possess unique gating properties: they activate at very negative voltages $(-50 \mathrm{mV})$, exhibit transient kinetics on sustained depolarization and deactivate slowly on repolarization [10]. T-type channels have a unique functional role in controlling action potential generation, oscillatory cell activity, muscle contraction, hormone release, cell growth and differentiation $[45,64,71]$. One of the first biophysical characterisations of T-type channels was performed in sensory neurons of dorsal root ganglia (DRG) [7] in which they are highly expressed [20,51]. Increasing evidence indicates that these channels play a key role in modulating sensory neurons excitability, under both normal conditions and pain states $[1,28,61,72]$. Such studies designated the most abundant isoform of T-type channels expressed in rat DRG neurons (Cav3.2), as a novel pronociceptive channel and, consequently, as a potential therapeutic target for the treatment of acute and chronic pain [5].

TRPV1 is a non-selective cation channel localized predominantly in peripheral sensory neurons where it activates in response to various nociceptive stimuli [13, 23, 62]. TRPV1 is physiologically activated by heat, low $\mathrm{pH}$ and endocannabinoids, but it can also be activated by 
natural compounds (i.e. capsaicin, resiniferatoxin, piperine, etc.) or synthetic analogues (i.e. olvanil, arvanil, etc.). TRPV1 activation by capsaicin induces a nociceptive sensory neuron depolarization that translates in transient pain sensations in animals and humans $[14,35]$. Because of its functional selectivity, capsaicin has proven to be an extremely useful functional marker for identifying neurons specialized in sensing unpleasant or painful (noxious) stimuli [12]. Paradoxically, exposure to capsaicin, after a brief excitatory pronociceptive response, "desensitizes" nociceptive sensory neurons and leads to long-lasting pain relief. Topical application of capsaicin and other TRPV1 agonists to the skin has been found helpful in the treatment of painful states in traditional and contemporary medicine $[42,52,57]$. Capsaicin analogues are currently in different phases of clinical trials mainly in the form of highconcentration topical patches (NGX-4100, NeurogesX) [3].

The analgesic effect of capsaicin and analogues is due to several mechanisms, including desensitisation of TRPV1 itself and a transient desensitisation of nerve terminals to multiple unrelated stimuli. At higher doses, capsaicin promotes nerve terminal degeneration. Reversible nerve terminal desensitisation could occur by different mechanisms. A possible one is the TRPV1-mediated inhibition of HVA channels that occurs as a consequence of $\mathrm{Ca}^{2+}$ influx and $\mathrm{Ca}^{2+}$-dependent down-regulation of the channels. Indeed, capsaicin and other TRPV1 agonists can both inhibit HVA $\mathrm{Ca}^{2+}$ channels in DRG neurons somata [4, 67, $68]$ and depress excitatory synaptic transmission at the level of the spinal cord [69]. On the other hand, capsaicin effects on T-type channels have not been thoroughly investigated.

Here, we provide clear evidence for a marked TRPV1mediated inhibition of functional T-type channels in rat DRG neurons. We found that the degree of inhibition of T-type channels is related to the capsaicin-induced $\mathrm{Ca}^{2+}$ currents and produces no changes to channel gating. Despite $\mathrm{Ca}^{2+}$ influx through TRPV1 channels is drastically attenuated in solutions containing $\mathrm{Na}^{+}$as the main permeating ion, our findings shed new light on the multiple downstream targets of TRPV1 activation: capsaicin-induced activation of TRPV1 inhibits not only HVA channels and synaptic transmission but also Ttype channels and therefore neuronal excitability in pain states. These effects may be crucial for understanding the analgesic action of capsaicin and its analogues.

\section{Materials and methods}

\section{Isolation of DRG neurons}

All procedures were performed in accordance with the guidelines established by the UK Home Office. Male Sprague-Dawley rats (3-6 weeks old; Harlan, UK) were killed by exposure to a rising concentration of $\mathrm{CO}_{2}$ followed by cervical dislocation. The DRGs were quickly removed and transferred into F12 culture medium (Gibco) supplemented with $10 \%$ fetal bovine serum (Gibco) and $1 \%$ penicillin/streptomycin (Cambrex). After removal of attached nerves and surrounding connective tissues, the DRGs were minced with fine spring scissors, and the ganglion fragments were enzymatically dissociated (collagenase $0.125 \%$ for $60 \mathrm{~min}$ at $37^{\circ} \mathrm{C}$ followed by trypsin $0.25 \%, 10 \mathrm{~min}$ ). After further mechanical dissociation, the cells were centrifuged through a bovine serum albumin gradient $(15 \%)$. Sensory neurons were plated in four-well plastic dishes treated with poly-D-lysine $(0.1 \mathrm{mg} / \mathrm{ml})$ and laminin $(5 \mu \mathrm{g} / \mathrm{ml})$ and kept for at least $24 \mathrm{~h}$ before electrophysiological recordings.

\section{Electrophysiological recordings}

Patch electrodes with a resistance of $\sim 2-4 \mathrm{M} \Omega$ were pulled from GC150TF-10 glass capillaries (inner diameter $1.17 \mathrm{~mm}$, outer diameter $1.5 \mathrm{~mm}$; Harvard Apparatus, Holliston, MA) using a micropipette puller and then fire-polished. $\mathrm{Ca}^{2+}$ currents were recorded in the whole-cell configuration using an Axopatch 200A amplifier and pClamp 9.0 software (Axon Instruments, Union City, CA, USA). After wholecell configuration was established, the cell membrane capacitance and series resistance were electronically compensated. $\mathrm{Ca}^{2+}$ currents were elicited by ramp commands $(0.5 \mathrm{~V} / \mathrm{s})$ starting from a holding potential of $-90 \mathrm{mV}$. Fast capacitative transients during step depolarization were minimized on-line by the patch-clamp analogue compensation. Uncompensated capacitative currents were further reduced by subtracting the averaged currents in response to $\mathrm{P} / 4$ hyperpolarizing pulses. All experiments were performed at room temperature $\left(22-24^{\circ} \mathrm{C}\right)$.

\section{Solutions and chemicals}

Unless otherwise indicated, the pipette filling solution contained $137 \mathrm{mM} \mathrm{CsCl}, 1 \mathrm{mM} \mathrm{MgCl} 2,10 \mathrm{mM}$ HEPES, $10 \mathrm{mM}$ EGTA and $1 \mathrm{mM}$ Mg-ATP (pH 7.3 adjusted with $\mathrm{CsOH}$, osmolarity $305 \mathrm{mOsm}) . \mathrm{Ca}^{2+}$ currents were recorded using an extracellular solution containing $135 \mathrm{mM}$ tetraethylammonium (TEA)- $\mathrm{Cl}, 1 \mathrm{mM} \mathrm{MgCl}_{2}$, $10 \mathrm{mM} \mathrm{CaCl}_{2}, 10 \mathrm{mM}$ HEPES and $11 \mathrm{mM}$ glucose (pH 7.3 adjusted with TEA-OH, osmolarity $320 \mathrm{mOsm}$ ). For recording $\mathrm{Ba}^{2+}$ currents through TRPV1 channels, extracellular calcium was replaced with an equivalent concentration of barium $(10 \mathrm{mM})$. Capsaicin and capsazepine were dissolved in DMSO to make a stock solution and were kept at $-20^{\circ} \mathrm{C}$. The final concentration of DMSO was less than $0.1 \%(\mathrm{v} / \mathrm{v})$, which did not affect membrane currents and intracellular $\mathrm{Ca}^{2+}$ concentration. The stock solutions were 
further diluted in the extracellular solution just before use. Cells in the recording chamber were continuously perfused with extracellular solution. Drugs and chemicals were purchased from Sigma.

\section{Data analysis}

Data were analyzed using the ClampFit software program (Axon Instruments, Union City, CA, USA) The percent of inhibition of $\mathrm{Ca}^{2+}$ currents was calculated as the ratio of the peak of $\mathrm{Ca}^{2+}$ current recorded after 2.5 min following capsaicin application vs. the peak of control $\mathrm{Ca}^{2+}$ current (recorded before capsaicin application). Data are given as means \pm standard error of the mean (s.e.m.) for $n$ cells. Statistical significance $(P<0.05)$ was calculated by means of Student's $t$ test for unpaired data.

\section{Results}

TRPV1 and T-type channels in DRG neurons

Based on cell size, DRG neurons have been classified as small (C-type, cell capacitance $<30 \mathrm{pF}$ ), medium (A $\delta$ type, $30-75 \mathrm{pF})$ and large $(>75 \mathrm{pF})[16,48,51]$. Since TRPV1 is highly expressed in small and medium-sized sensory neurons [24] likely to be nociceptors, we focused our study on this subset of sensory neurons. Capsaicin application $(1 \mu \mathrm{M}, 30 \mathrm{~s})$ produced inward currents ranging from 100 to $5000 \mathrm{pA}$ in amplitude ( $28 \pm 4 \mathrm{pA} / \mathrm{pF}, n=39)$ (Fig. 1a). In agreement with previous studies we found that adult rat DRGs responded differently to capsaicin [22]. They could be separated into two groups: $59 \%$ responding with a large capsaicin-induced current density with an integral area under the curve of $>0.1 \mathrm{nC} / \mathrm{pF}$ (charge density influx) for a 30 -s capsaicin application and the remaining $41 \%$ with either no response or with a weak charge density influx $(<0.1 \mathrm{nC} / \mathrm{pF})$. When looking at the percentage of responding neurons as a function of cells size, $53 \%(n=18)$ of the small cells and $66 \%(n=21)$ of the medium-size cells were sensitive to capsaicin with a mean charge density influx of $0.34 \pm 0.06$ and $0.39 \pm 0.04 \mathrm{nC} / \mathrm{pF}$, respectively (Fig. 1b).

Previous studies demonstrated the existence of T-type $\mathrm{Ca}^{2+}$ currents in cultured rat DRG neurons $[9,28,53]$. Under our experimental conditions $\left(10 \mathrm{mM}\right.$ external $\left.\mathrm{Ca}^{2+}\right)$ we could identify cells showing no T-type currents, cells with T-type smaller than HVA currents and cells with Ttype larger than HVA currents. Figure 1c shows examples of $\mathrm{Ca}^{2+}$ currents recorded from three DRG neurons representative of the subtypes mentioned previously. The traces are $\mathrm{Ca}^{2+}$ currents evoked by a ramp command with a slope of $0.5 \mathrm{~V} / \mathrm{s}$ from the $-90 \mathrm{mV}$ holding potential $\left(V_{\mathrm{h}}\right)$ to $+60 \mathrm{mV}$. Currents recorded from the first DRG subtype exhibited $I-V$ characteristics with a single peak at $-7 \pm$ $2 \mathrm{mV}(n=25)$, suggesting a predominance of HVA $\mathrm{Ca}^{2+}$ channels (Fig. 1c, top panel). The second cell, in addition to the HVA $\mathrm{Ca}^{2+}$ current, shows the classical low-threshold "shoulder" of T-type $\mathrm{Ca}^{2+}$ channels around $-37 \pm 2 \mathrm{mV}(n=$ 47) (Fig. 1c, middle panel). A small proportion of neurons showed T-type currents larger than the high-threshold currents with the peak at more negative voltages $(-44 \pm$ $5 \mathrm{mV}, n=10$ ) (Fig. 1c, lower panel). From a total of 82 neurons tested, $32 \%$ had no T-type current, $56 \%$ had the "classical" response in which the T-type current amplitude is a fraction of the HVA peak and $12 \%$ had very large T-type currents (comparable to the HVA).

In agreement with previous studies [54] we observed Ttype currents in $66 \%(n=35)$ and $72 \%(n=21)$ of small and medium-sized DRG neurons, respectively (Fig. 1d). The average T-type current densities were $43 \pm 12 \mathrm{pA} / \mathrm{pF}(n=35)$ and $24 \pm 9 \mathrm{pA} / \mathrm{pF}(n=21)$ in small and medium neurons while the HVA $\mathrm{Ca}^{2+}$ currents were $138 \pm 12 \mathrm{pA} / \mathrm{pF}(n=52)$ and $103 \pm 12 \mathrm{pA} / \mathrm{pF}(n=29)$ in small and medium neurons, respectively. Interestingly, we noticed that a large population of the DRG neurons ( $42 \%$ of the small and $50 \%$ of the medium neurons) co-expressed TRPV1 and T-type $\mathrm{Ca}^{2+}$ channels.

A series of biophysical and pharmacological tests were also performed to confirm the contribution of Ttype currents to the "low-threshold" peak observed in the ramp recordings. To characterize the fast inactivation properties of T-type channels we used a two-pulse protocol that allowed a clear separation of T-type and HVA currents. The initial pre-pulse from $V_{\mathrm{h}}=-90 \mathrm{mV}$ to $-40 \mathrm{mV}$ activated and fully inactivated the T-type current which was then unavailable during the subsequent ramp to $+60 \mathrm{mV}$ or test pulse to $-10 \mathrm{mV}$ (Fig. 2a, b). Thus, low-voltages test pulses could separate T-type from HVA $\mathrm{Ca}^{2+}$ currents as shown in previous studies $[9,45]$. We also estimated the time constant of inactivation $\left(\tau_{\text {inact }}\right)$ during pulses at -30 and $-20 \mathrm{mV}$ where T-type channels are maximally activated and their fast inactivation reaches minimal asymptotic values [9]. We found mean values of 23.7 and $17.9 \mathrm{~ms}(n=15)$, in excellent agreement with previously reported $\tau_{\text {inact }}$ values for $\mathrm{T}$ type currents $[44,45]$. Finally, we found that $50 \mu \mathrm{M} \mathrm{Ni}^{2+}$ caused a potent and reversible block of the low-threshold peak $(92 \pm 3 \%, n=7)$ and a much smaller reduction of the HVA peak $(35 \pm 4 \%, n=7 ; P<0.001)$ (Fig. 2 c).

Capsaicin inhibits both T-type and HVA $\mathrm{Ca}^{2+}$ currents via a TRPV1-mediated mechanism

To study the inhibitory effects of capsaicin on T-type and HVA channels, $\mathrm{Ca}^{2+}$ currents were elicited by ramp commands of $300 \mathrm{~ms}$ from -90 to $+60 \mathrm{mV}$ before capsaicin 
Fig. 1 Capsaicin-activated and T-type currents in DRG neurons. a Representative inward current trace of a DRG neuron responding to a $30 \mathrm{~s}$ application of $1 \mu \mathrm{M}$ capsaicin in whole-cell patch-clamp conditions.

The DRG neuron was held at $-90 \mathrm{mV}$ potential. b Distribution of small (capacitance $<30 \mathrm{pF}, n=18$ ) and medium-size cells (capacitance 30-75 pF,

$n=21)$ that responded to

capsaicin. Capsaicin-

sensitive cells had a charge density influx $>0.1 \mathrm{nC} / \mathrm{pF}$. That was calculated as the time integral of the current during $30 \mathrm{~s}$ capsaicin application. c

Representative

$\mathrm{Ca}^{2+}$ current traces evoked by ramp commands from -90 to $+60 \mathrm{mV}$ in three different sensory neurons. Large $\mathrm{HVA} \mathrm{Ca}^{2+}$ currents are present in all three cells and contributed to the peak at more positive potentials. The peak observed at more negative potentials (middle and bottom traces) corresponds to T-type $\mathrm{Ca}^{2+}$ current. d Cells exhibiting T-type and HVA currents are equally distributed in the two populations of small and medium-sized neurons a
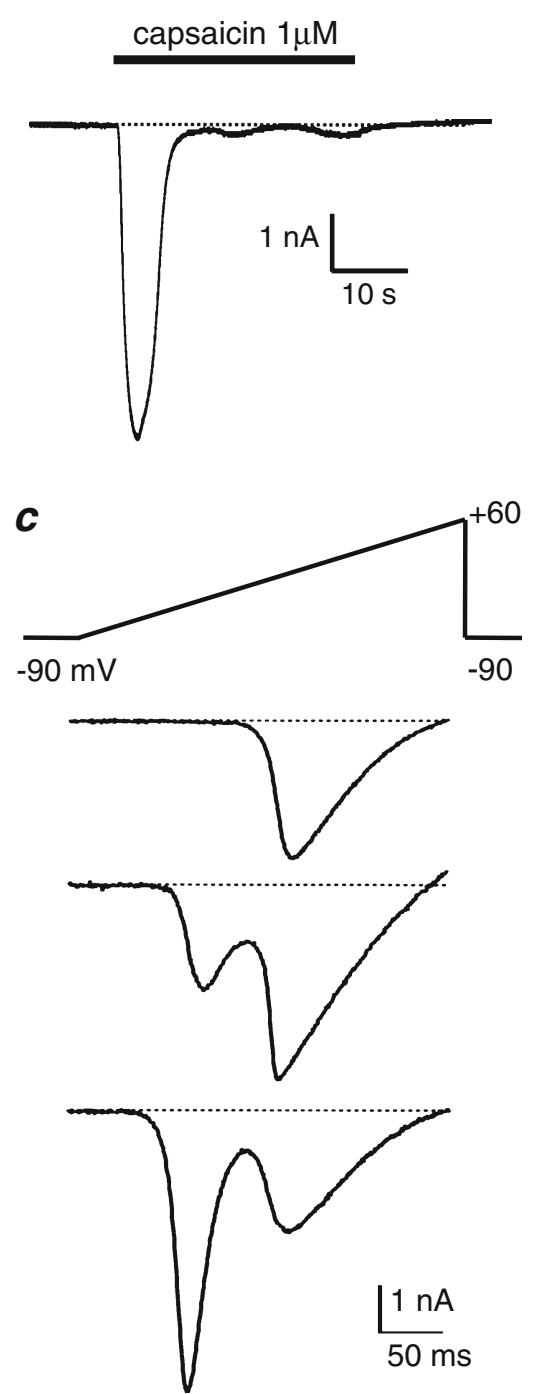
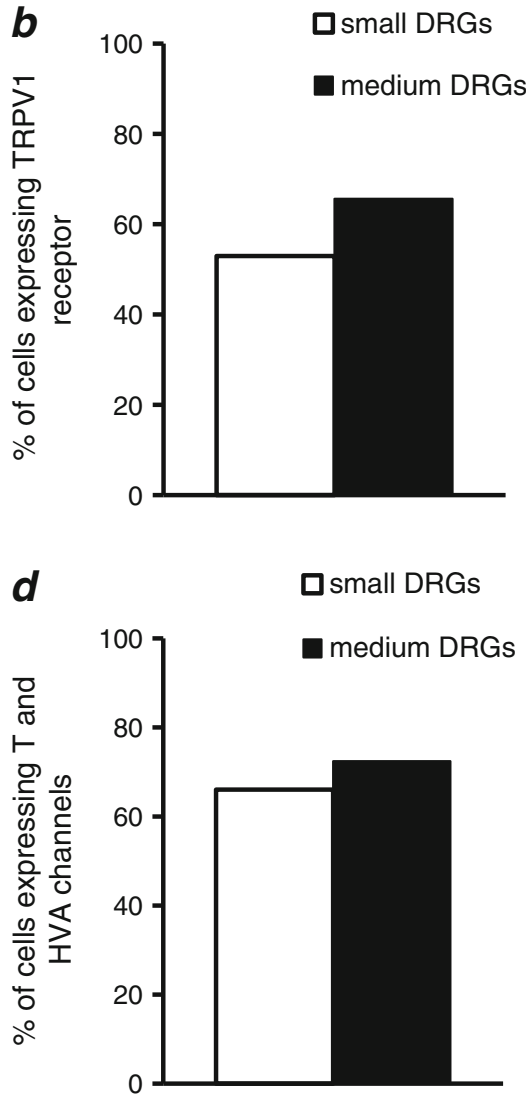

application $(1 \mu \mathrm{M}, 30 \mathrm{~s})$ and $2.5 \mathrm{~min}$ after capsaicin washout (Fig. 3a). The reason for waiting $2.5 \mathrm{~min}$ after capsaicin washout was that TRPV1 activation by capsaicin caused an increased outward current at positive potentials, most likely carried by a $\mathrm{Ca}^{2+}$-activated TEA-insensitive $\mathrm{K}^{+}$ channel or some unspecific leakage channel that distorted the time course of inward current and hampered a clear estimation of the $\mathrm{Ca}^{2+}$ reversal potential $\left(E_{\mathrm{Ca}}\right) \cdot E_{\mathrm{Ca}}$ requires being unchanged for comparing peak inward $\mathrm{Ca}^{2+}$ currents. We found that, on average, after $2.5 \mathrm{~min}$ the outward currents returned to normal and the peak of HVA and T-type currents recovered partially to settle at a constant value that was finally estimated. Figure $3 \mathrm{~b}$ shows the time course of peak T-type and HVA currents measured before and after the $30 \mathrm{~s}$ application of capsaicin. Notice the slight recovery of both currents following capsaicin removal. Inhibition of Ttype $\mathrm{Ca}^{2+}$ channels was clear also when currents were elicited by a series of step depolarization (from -50 to $-20 \mathrm{mV}$ ) in $10 \mathrm{mV}$ increments from $V_{\mathrm{h}}=-90 \mathrm{mV}$. T-type $\mathrm{Ca}^{2+}$ currents typically start activating at low voltages $\left(-50 \mathrm{mV}\right.$ in $\left.10 \mathrm{mM} \mathrm{Ca}^{2+}\right)$ and display their characteristic fast inactivation during step depolarizations of $100 \mathrm{~ms}$ length (Fig. 3c). Inhibition was obvious at all test potentials.

Capsaicin induced rapid inward currents in 39 of the DRGs tested and caused a large inhibition of both T-type and HVA current amplitudes measured at their respective peak: $47 \pm 4 \%(n=30)$ and $49 \pm 5 \%(n=39)$ inhibition of Ttype and HVA currents, respectively (Fig. 4a). In contrast, in capsaicin-insensitive DRG neurons (i.e. in neurons expressing low densities of TRPV1) $1 \mu \mathrm{M}$ capsaicin had no significant effects on T-type or HVA currents (Fig. 4b). The small reduction of $\mathrm{Ca}^{2+}$ currents in these neurons is within the range of physiological "rundown" that we 
Fig. 2 Isolation of T-type currents. Three protocols were used to assess the contribution of T-type currents. a Left: ramp commands from -90 to $+60 \mathrm{mV}$, preceded (grey line) or not (black line) by a $100 \mathrm{~ms}$ prepulse to $-40 \mathrm{mV}$. Right: normalized reduction of T-type and HVA current peaks in experiments using the inactivation pre-pulse $(n=13)$. b Left: A double-pulse protocol with (grey line) or without (black line) a pre-pulse to $-40 \mathrm{mV}$ followed by a test pulse to $-10 \mathrm{mV}$. Right: Normalized reduction of the peak (Ip) and the steady-state current (Iss) in 17 cells with and 13 cells without the T-type current peak. c Left: The blocking effect of $50 \mu \mathrm{M} \mathrm{Ni}^{2+}$ on $\mathrm{Ca}^{2+}$ currents. The low-threshold peak is selectively blocked by $50 \mu \mathrm{M} \mathrm{Ni}^{2+}$ (92\% reduction) while the HVA peak is less affected (34\% reduction).

Right: inhibition of the T-type and HVA current peak a

$+60 \mathrm{mV}$

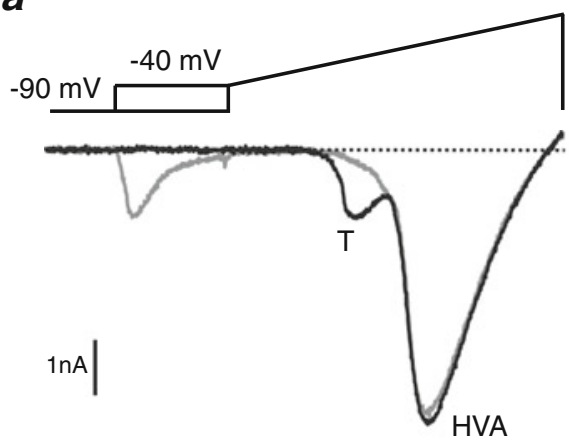

b
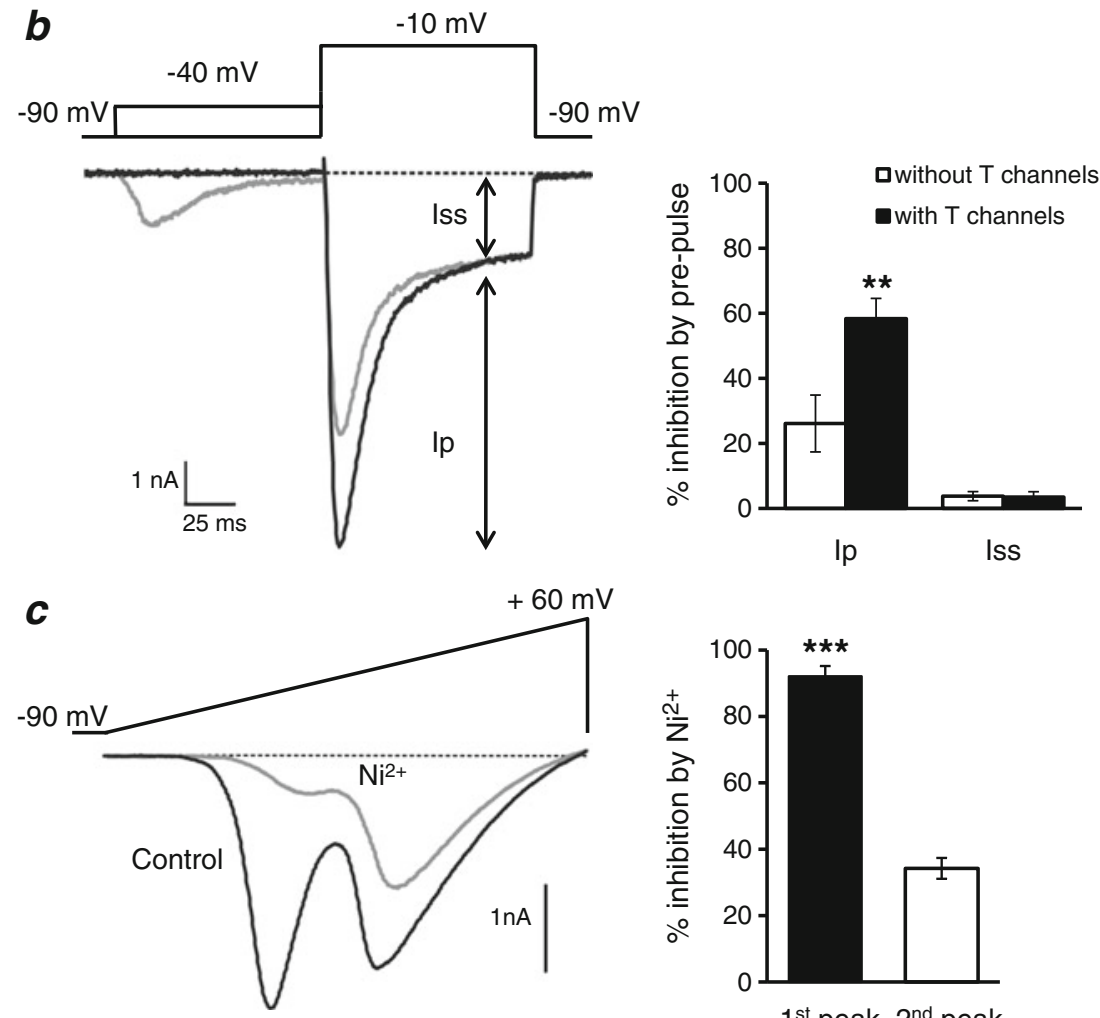

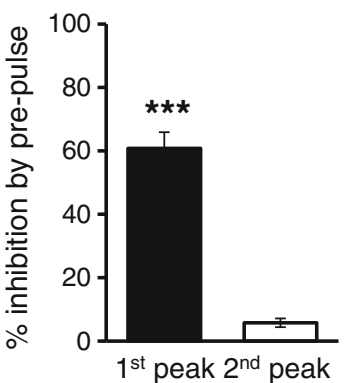

( $\mathrm{T}$ )

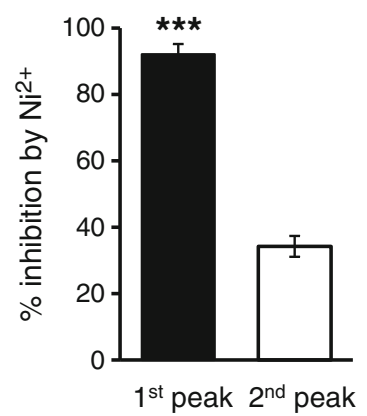

( T ) ( HVA)

normally observed in our culture conditions. To further confirm that the inhibition of T-type and HVA $\mathrm{Ca}^{2+}$ channels induced by capsaicin is specifically mediated by TRPV1 activation, we used a specific TRPV1 antagonist, capsazepine $[37,70]$. Capsazepine alone $(10 \mu \mathrm{M})$ did not produce any currents and had no effect on $\mathrm{Ca}^{2+}$ currents $(n=13)$. In all the DRG neurons exposed to capsazepine $(n=13)$, capsaicin failed to produce any inward current and had no inhibitory effect on T-type and HVA currents. Figure $4 \mathrm{c}$ shows an example of no response to capsaicin and no effect on T-type and HVA channels in the presence of the TRPV1 antagonist.

We found also that there was no differential inhibition of T-type and HVA Ca ${ }^{2+}$ channels based on cell size (Fig. 4d). T-type $\mathrm{Ca}^{2+}$ currents were inhibited by $44 \pm 5 \%$ and $49 \pm 7 \%$ in small $(n=14)$ and medium-sized $(n=16)$ DRG neurons, while $\mathrm{HVA} \mathrm{Ca}^{2+}$ currents were inhibited by $48 \pm 7 \%(n=18)$ and $50 \pm 6 \% \quad(n=21)$ in small and medium-sized cells, respectively. Given that under our experimental conditions $\left(\mathrm{Na}^{+}\right.$replaced by TEA) $\mathrm{Ca}^{2+}$ is the main cation flowing through TRPV1 channels, our findings suggest that inhibition of $\mathrm{Ca}^{2+}$ channels is somehow related to the influx of $\mathrm{Ca}^{2+}$ passing through TRPV1 receptors.

Capsaicin does not alter the gating properties of T-type channel in DRG cells

Given that activation of TRPV1 channels produces a marked reduction of T-type currents we next tested whether capsaicin affected the gating and conductance properties of 
Fig. 3 Capsaicin inhibits T-type and $\mathrm{HVA} \mathrm{Ca}^{2+}$ currents in small and medium-sized DRG neurons. a Representative traces showing $\mathrm{Ca}^{2+}$ currents before and after application of $1 \mu \mathrm{M}$ capsaicin in a capsaicinsensitive DRG neuron. $\mathrm{Ca}^{2+}$ currents are evoked by a ramp command from -90 to $+60 \mathrm{mV}$ with a slope of $0.5 \mathrm{~V} / \mathrm{s}$, from a $V_{\mathrm{h}}=-90 \mathrm{mV}$. Notice the 2 peak of currents. b Time course of T-type and HVA currents inhibition induced by $30 \mathrm{~s}$ application of $1 \mu \mathrm{M}$ capsaicin. The bars indicate the time of capsaicin exposure. c Representative traces showing $\mathrm{Ca}^{2+}$ currents before and after application of $1 \mu \mathrm{M}$ capsaicin in a capsaicinsensitive DRG neuron. $\mathrm{Ca}^{2+}$ currents are evoked by consecutive step depolarizations at low voltages from a holding potential $V_{\mathrm{h}}=-90 \mathrm{mV}$
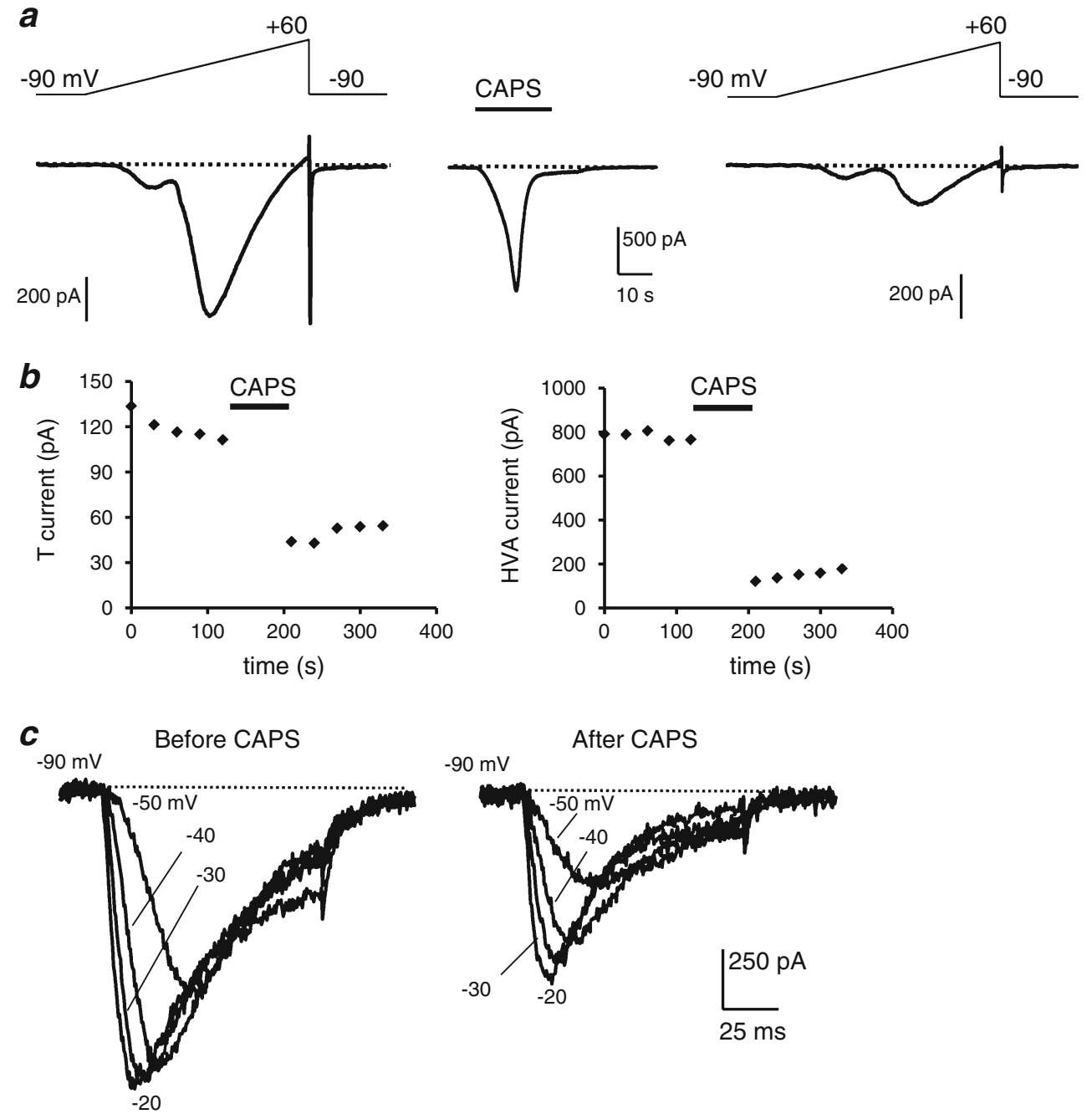

low-voltage activated T-type channels. We assessed steadystate inactivation by a double-pulse protocol using preconditioning pulses of $3.5 \mathrm{~s}$ from -100 to $-30 \mathrm{mV}$ (steps of $10 \mathrm{mV}$ ) and measured the peak current amplitude at $-30 \mathrm{mV}$ test potential (Fig. 5a). Figure 5b shows that the inactivation curve versus voltage was well described by a Boltzmann function with $V_{1 / 2}=-61.5 \pm 0.7 \mathrm{mV}$ and $k=5.3 \pm$ $0.5 \mathrm{mV}$ before capsaicin application, which is not significantly different from that after capsaicin application $\left(V_{1 / 2}=-60 \pm 2 \mathrm{mV}, k=9 \pm 2 \mathrm{mV} ; n=7, P>0.05\right)$. The same was found for the T-type channel conductance versus voltage that was calculated at the peak of the current at potentials between -70 and $-20 \mathrm{mV}$ and fitted by a Boltzmann function with $V_{1 / 2}=-47 \pm 2 \mathrm{mV}$ and $k=10 \pm$ $2 \mathrm{mV}$ before and $V_{1 / 2}=-46 \pm 3 \mathrm{mV}$ and $k=14 \pm 5 \mathrm{mV}$ after capsaicin application $(n=8 ; P>0.05)$. Capsaicin had also no significant effect on the kinetics of the T-type activation and deactivation. Activation was measured as the rise time spent to go from $10 \%$ to $90 \%$ of the peak current $\left(t_{10-90}\right.$; Fig. 5c) while deactivation was derived from the time constant of tail currents $\left(\tau_{\text {deact }}\right)$ on return to negative potentials ( -100 to $-50 \mathrm{mV}$; Fig. $5 \mathrm{~d})$. Tail currents are the major "fingerprint" of T-type channel gating [8, 9, 45] and, at return potentials near $-50 \mathrm{mV}$, help distinguish T-type channels from HVA channels [8], in particular from R-type channels [50]. Figure 5d shows that capsaicin has little effect on the kinetics of T-type currents deactivation, which is very slow at potentials more positive than $-60 \mathrm{mV}$, in good agreement with values reported previously for both native T-type channels in rat DRG [43, 60] and recombinant rat $\mathrm{Ca}_{\mathrm{V}} 3.2$ subunits $[17,41]$. Taken all together these experiments suggest that capsaicin, while reducing current amplitudes, does not change significantly the activation, deactivation and steady-state inactivation of T-type channels.

Capsaicin-induced T-type and HVA channel inhibition is $\mathrm{Ca}^{2+}$-dependent

Since TRPV1 channels are highly permeable to $\mathrm{Ca}^{2+}$ and because we found that the degree of capsaicin-induced inhibition of T-type and HVA currents is proportional to the 
Fig. 4 T-type and HVA $\mathrm{Ca}^{2+}$ currents inhibition induced by capsaicin is mediated by TRPV1 activation. a Inhibition of T-type and $\mathrm{HVA} \mathrm{Ca}^{2+}$ currents in capsaicin-sensitive (charge density influx $>0.1 \mathrm{nC} / \mathrm{pF}$ ) and capsaicin-insensitive (charge density influx $<0.1 \mathrm{nC} / \mathrm{pF}$ ) DRG neurons $(* * * P<0.001)$. b Representative traces showing $\mathrm{Ca}^{2+}$ currents before (black trace) and after (grey trace) application of $1 \mu \mathrm{M}$ capsaicin in a capsaicininsensitive cell. $\mathbf{c ~} \mathrm{Ca}^{2+}$ current traces showing that $10 \mu \mathrm{M}$ capsazepine abolished the inhibitory effect of $1 \mu \mathrm{M}$ capsaicin on Ttype and HVA currents. d Relationship between the inhibition of T-type and HVA $\mathrm{Ca}^{2+}$ currents and the size of the cells
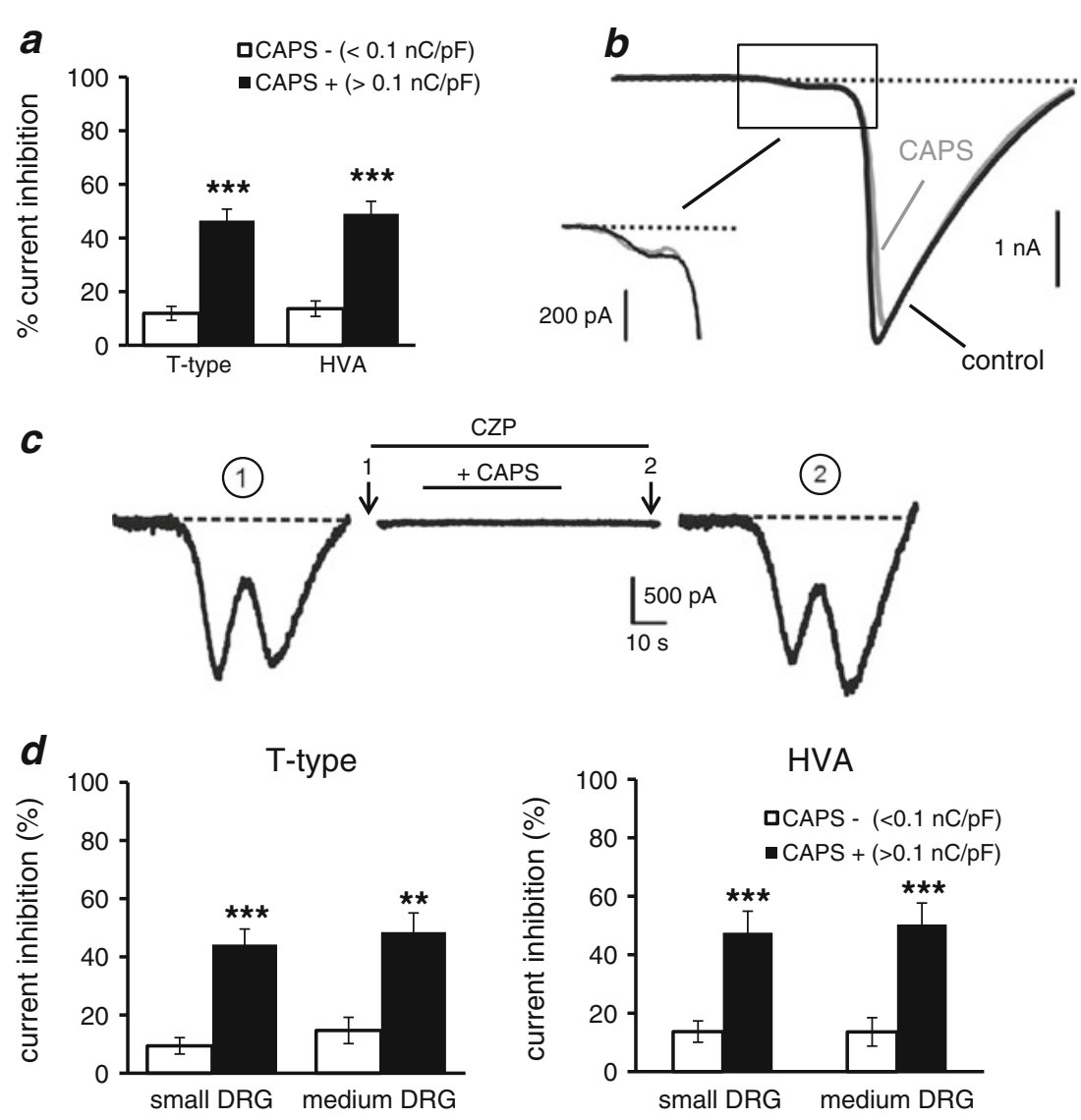

amplitude of capsaicin currents, we next investigated whether extracellular $\mathrm{Ca}^{2+}$ was indeed required for capsaicin-induced inhibition of T-type and HVA channels. A previous study [67] reported that the inhibitory effects of capsaicin on HVA currents were prevented by inclusion of $10 \mathrm{mM}$ BAPTA, a fast $\mathrm{Ca}^{2+}$ chelator in the intracellular solution. In order to determine whether BAPTA had the same effect on capsaicininduced T-type channel inhibition, we tested the effects of replacing EGTA with 10 or $20 \mathrm{mM}$ BAPTA in the pipette. Following cell membrane rupture and achievement of the whole-cell configuration, the intracellular solution exchange was allowed for $5 \mathrm{~min}$ before examining the effects of capsaicin. We found that $10 \mathrm{mM}$ BAPTA was not able to prevent the capsaicin-induced inhibition of either the T-type $(47 \pm 16 \%, n=3)$ or HVA currents $(48 \pm 9 \%, n=5)$, while increased BAPTA concentrations $(20 \mathrm{mM})$ could largely prevent both T-type $(19 \pm 8 \%, P<0.01)$ and HVA channels inhibition $(16 \pm 6 \%, P<0.001)$ in $n=11$ cells (Fig. 6a).

To further assess the importance of $\mathrm{Ca}^{2+}$ on the inhibition of T-type and HVA currents, we tested the effects of replacing $\mathrm{Ca}^{2+}$ with $\mathrm{Ba}^{2+}$. Capsaicin responses with $10 \mathrm{mM} \mathrm{Ba}^{2+}$ were smaller in amplitude than the currents recorded with $\mathrm{Ca}^{2+}$, supporting previous observations that $\mathrm{Ca}^{2+}$ permeates capsaicin-gated channels more readily than $\mathrm{Ba}^{2+}$ [33]. Specifically, both the mean current amplitudes and the total charge load measured in $\mathrm{Ba}^{2+}$ were smaller than those in $\mathrm{Ca}^{2+}$ with values of $12.1 \mathrm{pA} / \mathrm{pF}$ and $0.21 \pm 0.03 \mathrm{nC} / \mathrm{pF} \quad(n=7)$ versus $28 \pm 4 \mathrm{pA} / \mathrm{pF}$ and $0.42 \pm 0.04 \mathrm{nC} / \mathrm{pF}(n=39)$, respectively. Correspondingly, the inhibition of T-type $(7 \pm 5 \%, n=7)$ and HVA currents $(16 \pm 7 \%, n=7)$ was largely prevented in $10 \mathrm{mM} \mathrm{Ba}{ }^{2}$, confirming the essential role of $\mathrm{Ca}^{2+}$ entry through TRPV1 channels in the inhibition of both T-type and HVA channels (Fig. 6b). The lack of inhibition of $\mathrm{Ca}^{2+}$ currents in the presence of extracellular $\mathrm{Ba}^{2+}$ was not a consequence of the smaller $\mathrm{Ba}^{2+}$ currents through TRPV1. Cells recorded in $10 \mathrm{mM}$ extracellular $\mathrm{Ca}^{2+}$ after a charge load comparable to $\mathrm{Ba}^{2+}(<0.5 \mathrm{nC} / \mathrm{pF})$ showed in all cases greater T-type and HVA Ca ${ }^{2+}$ currents inhibition: $42 \pm 5 \%(n=$ $21)$ and $41 \pm 5 \%(n=28)$, respectively.

It was also important to check whether under more physiological ionic conditions T-type and HVA $\mathrm{Ca}^{2+}$ were still inhibited by capsaicin. TRPV1 is a non-selective cation channel that permeates monovalent cations with an approximately tenfold preference for $\mathrm{Ca}^{2+}$ [12]. However, with high extracellular $\mathrm{Na}^{+}$concentrations the two ions compete for permeation and the fraction of $\mathrm{Ca}^{2+}$ flowing through TRPV1 is low [15]. In the next series of experiments we used an extracellular Tyrode solution (with $10 \mathrm{mM} \mathrm{Ca}^{2+}$ ) containing physiological levels of $\mathrm{Na}^{+}$, rather than the TEA-based extracellular solution used in the experiments of Figs. 1, 2, 3, 4 and 5, to verify whether the amount of $\mathrm{Ca}^{2+}$ passing through TRPV1 under these conditions is enough 

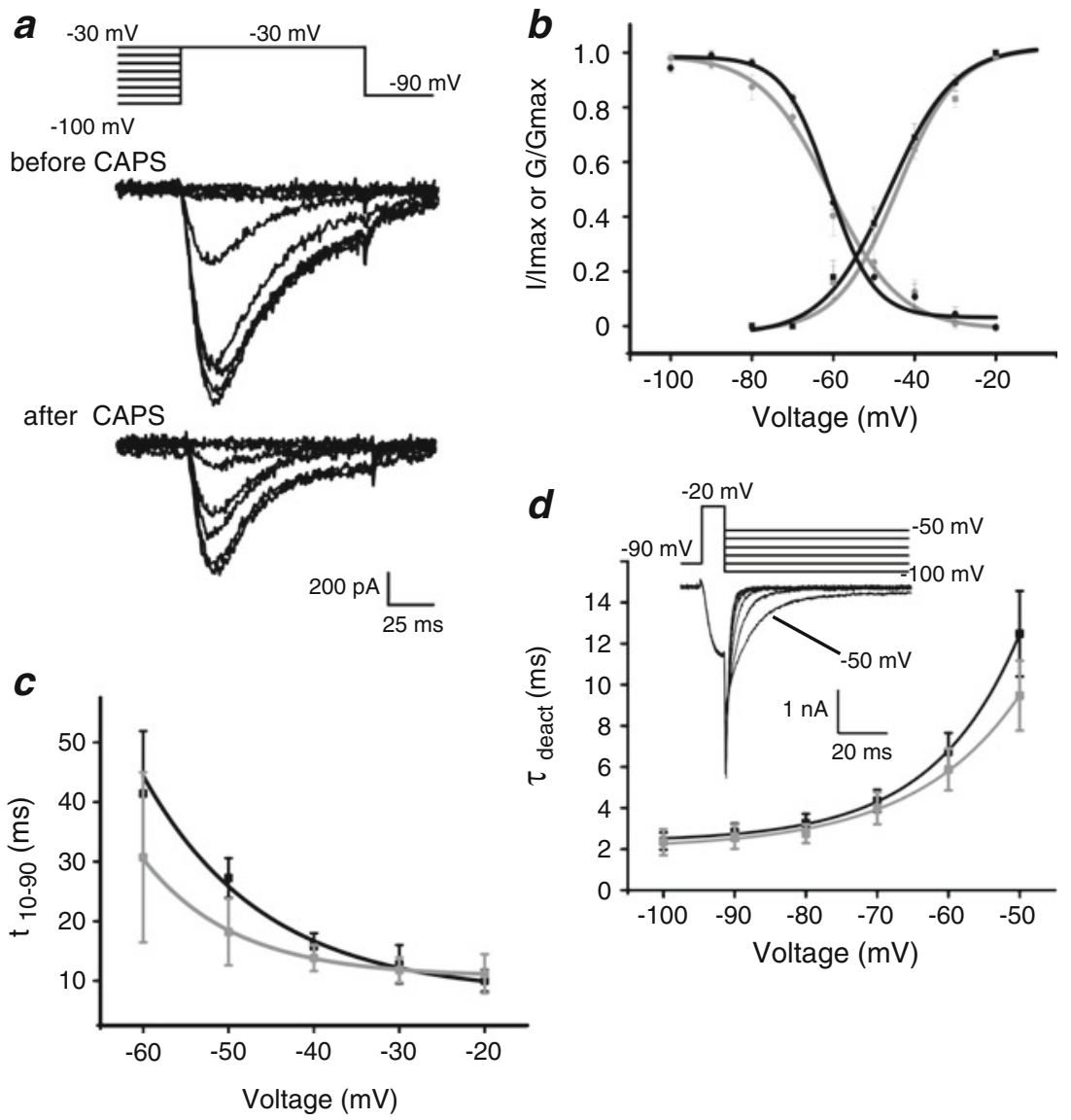

Fig. 5 The effect of capsaicin on the biophysical properties of T-type channels. a Representative current traces recorded in a cell before (left) and after (right) capsaicin application. Currents are evoked by steps to $-30 \mathrm{mV}$ after a $3.5 \mathrm{~s}$ pre-pulse at potentials from -100 to $-30 \mathrm{mV}$ in $10 \mathrm{mV}$ increments. b Left, steady-state inactivation curves obtained from $n=7$ cells before (black line) and after (grey line) capsaicin application. The continuous curves are Boltzmann functions best fitting the data points with half maximal inactivation of $V_{1 / 2}=$ $-61.5 \pm 0.7 \mathrm{mV}$ and slope factor $k=5.3 \pm 0.5 \mathrm{mV}$ (before) and $V_{1 / 2}=-60$ $\pm 2 \mathrm{mV}$ and $k=9 \pm 2 \mathrm{mV}$ (after). Right, voltage-dependent conductance of T-type currents. The normalized $\mathrm{Ca}^{2+}$ channels conductance was calculated as $I_{\text {peak }} /\left(V-V_{\text {rev }}\right)$ from $n=8$ cells before (black line) and after (grey line) capsaicin application and plotted in function of potentials. The extrapolated reversal potential for $\mathrm{Ca}^{2+}\left(V_{\text {rev }}\right)$ was taken to be $+55 \mathrm{mV}$. The continuous curves are Boltzmann functions

to induce T-type and HVA currents inhibition. Figure 6c shows indeed that under these conditions the inhibitory effect of capsaicin on T-type and HVA currents is largely prevented in all 6 neurons tested: $8 \pm 5 \%$ of inhibition for Ttype and $10 \pm 7 \%$ of inhibition for HVA currents.

Capsaicin-induced T-type and HVA channel inhibition is not mediated by calcineurin and calmodulin

Because the increase in intracellular $\mathrm{Ca}^{2+}$ appeared essential for the inhibitory effect of capsaicin on T-type and HVA $\mathrm{Ca}^{2+}$ channels, we next examined if calmodulin played a role in with $V_{1 / 2}=-47 \pm 2 \mathrm{mV}$ and $k=10 \pm 2 \mathrm{mV}$ (before) and $V_{1 / 2}=-46 \pm 3 \mathrm{mV}$ and $k=14 \pm 5 \mathrm{mV}$ (after). c Mean activation time measured as 10-90\% rise times in cells before (black line) and after (grey line) capsaicin application. Voltage-dependent activation is slower at negative test potentials but become nearly identical at $-30 \mathrm{mV}$. The curves are single exponentials with $k=14 \pm 6 \mathrm{mV}$ (before) and $k=11 \pm 9 \mathrm{mV}$ (after). d The graph represents mean time constants of deactivation determined in $n=7$ cells before (black line) and after (grey line) capsaicin application with $10 \mathrm{~ms}$ long depolarizing pulse from $V_{\mathrm{h}}$ of $-90 \mathrm{mV}$ to $-20 \mathrm{mV}$ followed by repolarizing pulses to the potentials indicated in $x$-axis . Deactivation currents were reasonably well fitted by single-exponential function at all potentials. Continuous lines are single-exponential functions with $k=12.2 \pm 0.4 \mathrm{mV}$ (before) and $k=$ $14.7 \pm 1.1 \mathrm{mV}$ (after). Inset, deactivation traces in a representative cell

this depressive action. The specific calmodulin antagonist W7 [21] was included in the pipette solution. In the presence of $\mathrm{W}-7(200 \mu \mathrm{M}) 1 \mu \mathrm{M}$ capsaicin still produced the usual large inhibition of T-type $(46 \pm 10 \%, n=7)$ and HVA currents $(42 \pm$ $8, n=9$ ), which was not significantly different from the effects of capsaicin in the absence of W-7 (Fig. 6d, left).

Calcineurin (protein phosphatase $2 \mathrm{~B}$ ) is a $\mathrm{Ca}^{2+}$-sensitive protein phosphatase that can be activated by $\mathrm{Ca}^{2+}$ influx. To determine if capsaicin inhibits $\mathrm{Ca}^{2+}$ currents through calcineurin-mediated dephosphorylation of calcium channels, $1 \mu \mathrm{M}$ deltamethrin, a specific inhibitor of calcineurin [19] was included in the pipette solution. Deltamethrin failed to 

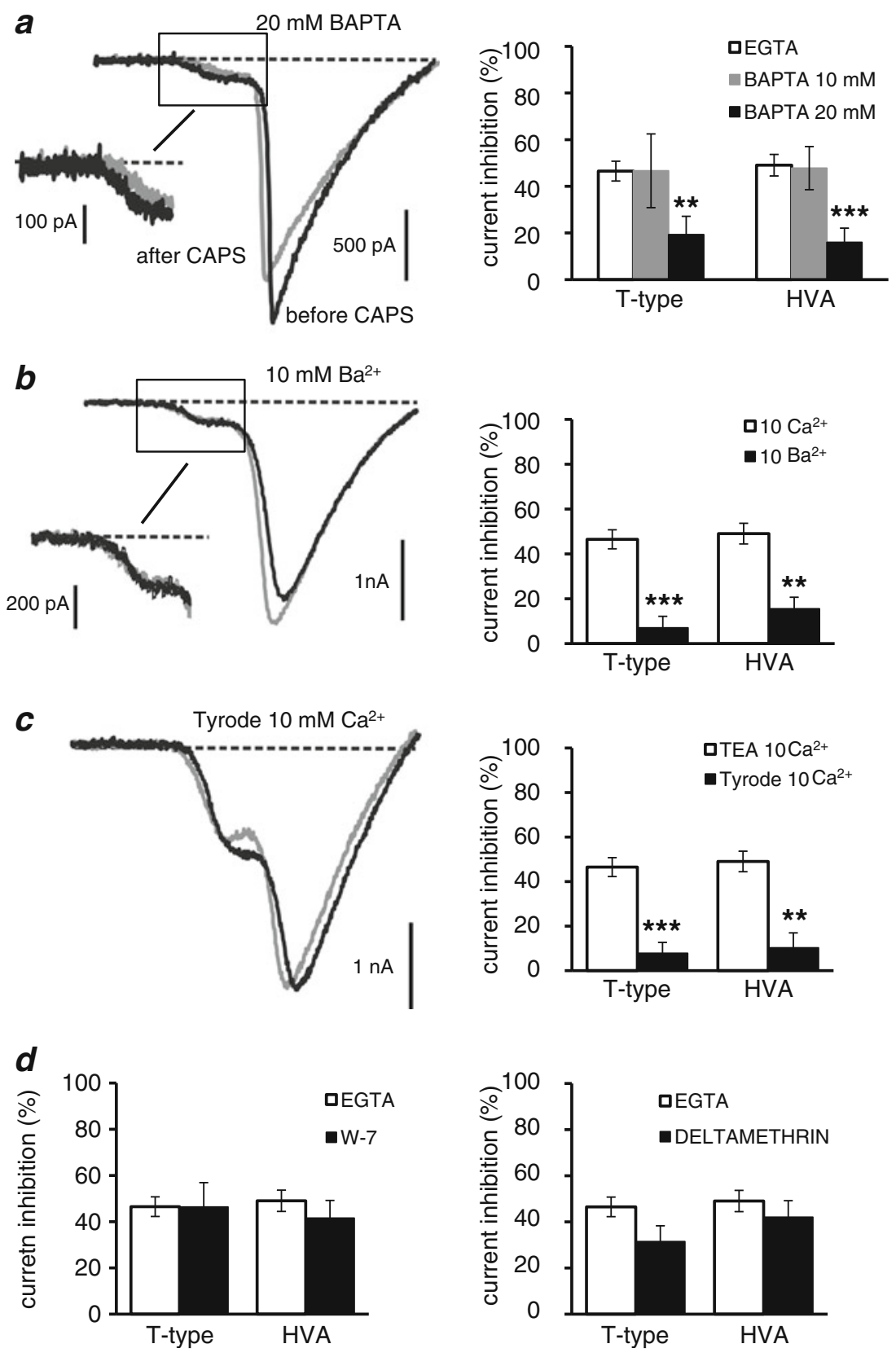

Fig. 6 Role of $\mathrm{Ca}^{2+}$ in the capsaicin-induced inhibition of T-type and HVA currents. Inhibition of T-Type and HVA currents was strongly reduced a using an external solution containing $20 \mathrm{mM}$ BAPTA $(n=$ 11) or $\mathbf{b}$ by replacing extracellular $\mathrm{Ca}^{2+}$ with a similar concentration of $\mathrm{Ba}^{2+}(n=7)$. $\mathbf{c}$ The inhibitory effect of $1 \mu \mathrm{M}$ capsaicin on T-type and HVA currents inhibitions is completely prevented when using Tyrode $\left(10 \mathrm{mM} \mathrm{Ca}^{2+}\right)$-like extracellular solution $\left(n=6\right.$; $* * * P<0.001$, ${ }^{* *} P<$

prevent the inhibitory effect of $1 \mu \mathrm{M}$ capsaicin on both Ttype (32 $\pm 7 \%)$ and HVA currents $(42 \pm 7 \%)$ in all ten neurons examined (Fig. 6d, right). Furthermore, intracellular application of higher concentration of deltamethrin $(10 \mu \mathrm{M})$ also failed to attenuate the inhibitory effect of $1 \mu \mathrm{M}$ capsaicin on $\mathrm{Ca}^{2+}$ currents in five additional DRG neurons (data not shown).
0.01). d Calmodulin and calcineurin are not involved in capsaicininduced T-type channel depression. Summary data showing that intracellular application of $200 \mu \mathrm{M} \mathrm{W}-7$ (calmodulin antagonist, left) and $1 \mu \mathrm{M}$ deltamethrin (inhibitor of calcineurin, right) failed to attenuate the inhibitory effect of $1 \mathrm{mM}$ capsaicin on T-type and HVA currents

\section{Discussion}

We have studied the effects of the TRPV1 agonist, capsaicin, on T-type and HVA $\mathrm{Ca}^{2+}$ channels in small and medium-size DRG neurons with the idea of searching for a possible cross-talk between these two channel moieties, both involved in pain perception and modulation. The 
small/medium-size DRG neurons are considered nociceptive sensory neurons belonging to the slowly conducting, unmyelinated $(\mathrm{C})$ and thinly myelinated $(\mathrm{A} \delta)$ fibers, respectively [25, 53]. $\mathrm{C}$ and $\mathrm{A} \delta$ fibers-related neurons express high densities of both TRPV1 $[11,13,26]$ and Ttype $\mathrm{Ca}^{2+}$ channels $[54,55,59]$. We found that the T-type channels of DRG neurons can be effectively downregulated by the large quantity of $\mathrm{Ca}^{2+}$ entering the cells during TRPV1 stimulation and facilitated by the possible co-localization of these two channel entities in membrane nano-microdomains.

TRPV1 and T-type channels are coexpressed in rat DRG neurons

Evidence for the expression of T-type and TRPV1 channels in rat DRG cells is unequivocal, and our data strongly support this view. As shown in Figs. 1, 2, 3 and 5, T-type channels in rat DRG neurons give rise to a transient $\mathrm{Ca}^{2+}$ current peaking around $-30 \mathrm{mV}$ in $10 \mathrm{mM} \mathrm{Ca}^{2+}$ and originate a "low-threshold peak" during ramp commands $[7,41]$. T-type $\mathrm{Ca}^{2+}$ channels inactivate rapidly in a timedependent and voltage-dependent manner [9, 45] and deactivate about ten times slower than HVA channels $[6$, 50]. These features are typical of native $[8,9]$ and cloned "low-voltage-activated" T-type channels $[17,34,46]$. In addition, the pharmacological and kinetic analysis of $\mathrm{Ca}^{2+}$ currents suggests that the low-voltage-activated $\mathrm{Ca}^{2+}$ currents are likely carried by the Cav3.2 isoform, the most abundant subtype of T-type channel expressed in rat DRG neurons [5, 28, 35, 55, 59]. T-type currents have deactivation kinetics very similar to those reported previously in rat DRG neurons $[28,43,60]$ as well as recombinant rat Cav3.2 $\mathrm{Ca}^{2+}$ channels [41]. These currents are also sensitive to low concentrations of $\mathrm{Ni}^{2+}(50 \mu \mathrm{M})$, as reported for DRG neurons and Cav3.2 subunits, while much higher concentrations are required to half-block Cav3.1 $(250 \mu \mathrm{M})$ and Cav3.3 $(216 \mu \mathrm{M}) \mathrm{Ca}^{2+}$ channels $[36,45]$.

Concerning the expression of TRPV1 channels we found that the percentage of cells responding to capsaicin (58\%) is consistent with previous studies in rat DRG neurons (64\%) [22]. Although several studies have suggested that smaller cells may be more sensitive to capsaicin [22], we show that only $54 \%$ of the small and $64 \%$ of the medium cells are responsive to the vanilloid. In intact DRGs, C-fibers tend to be associated with cells that are smaller in diameter and are more sensitive to capsaicin than A $\delta$ fibers [38]. However, a previous study [47] reported that $100 \%$ of cells with a cross area of about $800-1000 \mu^{2}$ (medium) were capsaicinsensitive, while in DRGs with a cross area of $600 \mu \mathrm{m}^{2}$ or less (small), capsaicin evoked an inward current only in $33 \%$ of tested cells. In large cells, with a cross area greater than $1000 \mu \mathrm{m}^{2}, 28 \%$ responded to capsaicin with an inward current. Capsaicin activation of TRPV1 is able to depolarize and cause $\mathrm{Ca}^{2+}$ influx in sensory neurons, leading to an enhanced excitatory drive and transient pain sensation. However, this is followed by an overall "silencing" of the neurons themselves. Systemic administration of moderate capsaicin concentrations will ultimately desensitize some types of $A \delta$ and $C$ fibers without affecting $A \beta$ mechanoreceptors [32, 58]. The ability of capsaicin to selectively desensitize sensory neurons is important for understanding its clinical efficacy in relieving pain produced by a variety of ailments [57].

TRPV1 and T-type channel coupling is $\mathrm{Ca}^{2+}$-dependent and requires high doses of BAPTA for uncoupling

A key finding of the present study is the high degree of coexpression of TRPV1 (capsaicin-responsive cells) and T-type channels in rat DRGs (45\%). We were therefore intrigued by the possibility of a cross-talk between these two channel types. It has been shown that capsaicin inhibits voltage-gated $\mathrm{Na}^{+}$ channels and action potentials in capsaicin-sensitive DRG and trigeminal neurons, by a mechanism involving secondmessenger pathways, including cAMP [39, 56]. More relevant to the present report, HVA channels of sensory neurons have been shown to be inhibited by both capsaicin [67] and olvanil [68], a natural and synthetic TRPV1 agonist, respectively. We here show, for the first time, that TRPV1 activation by capsaicin inhibits not only HVA channels but also T-type channels. This occurs without changes in T-type channel gating, pointing to specific changes in the density of functioning channels.

As T-type channels at the DRG somatic level are known to play a key role in the control of sensory neuron excitability in both physiological conditions $[45,66,71]$ and pain states [28, 29], the TRPV1-mediated inhibition of T-type channels reported here has potential overall consequences on nociceptive signals induction and transmission $[18,30,31]$.

We found that the degree of inhibition of T-type and HVA channels by TRPV1 activation is rather similar and occurs in both small and medium-size DRGs. The inhibitory effect of capsaicin on both T-type and HVA channels is mediated by activation of TRPV1 receptors, since in cells that do not respond (or respond weakly) to capsaicin we did not observe any $\mathrm{Ca}^{2+}$ channel inhibition. The degree of T-type and HVA current inhibition was found related to the capsaicin-evoked currents. TRPV1 activation probably initiates a complex cascade of intracellular events in which intracellular $\mathrm{Ca}^{2+}$ elevation has an important role. TRPV1 is highly permeable to $\mathrm{Ca}^{2+}[13,62]$, and capsaicin can induce substantial $\mathrm{Ca}^{2+}$ influx into DRG neurons. We therefore explored the role of intracellular and extracellular 
$\mathrm{Ca}^{2+}$ in capsaicin-induced inhibition of T-type and HVA channels. Intracellular dialysis with high doses $(20 \mathrm{mM})$ of the fast $\mathrm{Ca}^{2+}$ buffer BAPTA [63] and replacement of $\mathrm{Ca}^{2+}$ with $\mathrm{Ba}^{2+}$ largely prevent the inhibitory effect of capsaicin on T-type and HVA channels, suggesting that the rise in intracellular $\mathrm{Ca}^{2+}$ is the key event in the capsaicin-mediated inhibition of voltage-gated $\mathrm{Ca}^{2+}$ channels and that TRPV1 channels are likely co-localized, within a membrane nanomicrodomain, with T-type and HVA $\mathrm{Ca}^{2+}$ channels. It is interesting to notice that the functional coupling of L-type to $\mathrm{BK}$ potassium channels is within tens of nanometers distance and is fully prevented by $10 \mathrm{mM}$ BAPTA in rat and mouse chromaffin cells [40, 49]. The estimated average distance of these two channel entities under physiological $\mathrm{Ca}^{2+}$ concentration $(2 \mathrm{mM})$ is between 50 and $160 \mathrm{~nm}$, i.e. in a membrane nano-microdomain. It is also important to notice that an increase of intracellular $\mathrm{Ca}^{2+}$ per se is not sufficient for down-regulating T-type channels. Indeed, elevation of $\left[\mathrm{Ca}^{2+}\right]_{\mathrm{i}}$ to $6 \mu \mathrm{M}$ using intracellular $\mathrm{Ca}^{2+}$ buffers has been shown not to affect the size and time course of LVA T-type currents in chick DRG neurons [9], while HVA currents are rapidly washed out.

Another intriguing finding of our study is that TRPV1induced inhibition of HVA and T-type calcium channels was strongly attenuated when experiments were performed in extracellular solutions containing normal physiological $\mathrm{Na}^{+}$ concentrations. All previous studies that demonstrated inhibition of HVA calcium channels following TRPV1 activation used extracellular solutions based on TEA as the main extracellular cation $[4,67,68]$. Under these conditions, because of the lower permeability of TRPV1 for TEA (based on the large molecular size), there is very low competition for $\mathrm{Ca}^{2+}$ ions during permeation. As a result, $\mathrm{Ca}^{2+}$ will be the main cation entering the cell during TRPV1 activation and will produce a large $\mathrm{Ca}^{2+}$ influx. In normal physiological solution, $\mathrm{Ca}^{2+}$ ions will strongly compete with $\mathrm{Na}^{+}$ions for permeation, which will finally lead to less $\mathrm{Ca}^{2+}$ influx into the cell. This can partially explain the results reported here and in previous studies [4, 67, 68]. On the one hand, this observation further strengthens our observation that T-type and HVA channels inhibition is strongly $\mathrm{Ca}^{2+}$-dependent, but on the other hand it raises further questions on the physiological relevance of this phenomenon. In this respect it is worth considering that, a recent study by Chung et al. [16] clearly demonstrated that permeability for $\mathrm{Ca}^{2+}$ versus $\mathrm{Na}^{+}$is a dynamic characteristic of TRPV1 channels that can increase up to fivefold during prolonged TRPV1 channel stimulation (several minutes). Moreover, $\mathrm{Ca}^{2+}$ selectivity can be further increased by PKC phosphorylation of TRPV1, making our present findings (i.e. inhibition of T-type and HVA $\mathrm{Ca}^{2+}$ channels) even more plausible under inflammatory conditions associated with PKC activation during tissue injury-induced hyperalgesia [65].
No evidence for calmodulin and calcineurin involvement in capsaicin-induced T-type channel depression

Many intracellular signaling events are triggered by a transient rise in cytoplasmatic $\mathrm{Ca}^{2+}$ concentrations. In particular, the $\mathrm{Ca}^{2+}$-dependent phosphatase calcineurin was shown to play an important role in the inhibition of HVA channels mediated by TRPV1 activation by either capsaicin or olvanil $[67,68]$. Also, $\mathrm{Ca}^{2+}$-calmodulin is likely to mediate the activation of calcineurin that ultimately causes the inhibition of HVA channels after TRPV1 stimulation with olvanil [68]. Unfortunately, our data support these previous findings only partially. In agreement with $\mathrm{Wu}$ et al. $[67,68]$ we found that W-7 (a calmodulin inhibitor) does not prevent capsaicin effects, while we could not confirm that deltamethrin (a calcineurin inhibitor) prevents the inhibitory action of capsaicin. We do not have a clear explanation for this discrepancy except that they could derive from substantial differences in the cell isolation protocols and culturing. Another possibility is that recordings were obtained from DRG neurons of different size and after different time lags from capsaicin application. Our recordings of T-type and HVA currents are from small to medium-size DRGs and taken after $2.5 \mathrm{~min}$ from capsaicin application, a time lag required for the returning of $E_{\mathrm{Ca}}$ reversal potential to the control value. A final remarkable difference between our recordings and those of $\mathrm{Wu}$ et al. $[67,68]$ is on the functional availability of T-type currents, which we recorded in $70 \%$ of the DRG neurons while they were not prevalent in the previous study. T-type channels expression is a fingerprint of small and mediumsized rat DRG neurons. Thus, we are confident that our reported effects derive from nociceptive neurons possessing T-type and TRPV1 channels. Apart from this, our data suggest that other $\mathrm{Ca}^{2+}$-dependent events, unrelated to calcineurin and $\mathrm{Ca}^{2+}$-calmodulin, are likely to mediate the modulation of the T-type channels. This includes direct $\mathrm{Ca}^{2+}$ binding to voltage-gated calcium channels or the involvement of other $\mathrm{Ca}^{2+}$-binding proteins which remain to be identified in future investigations. Regardless of the precise mechanism of action, it is worth stressing the importance of this newly uncovered tight coupling between TRPV1 and T-type (Cav3.2) channels, which is in line with increasing evidence that both T-type and TRPV1 channels can, individually, form functional complexes with other ion channels like $\mathrm{K}_{\mathrm{V}} 4$ [2], HCN1 [27] and KCNQ2/3 [73].

\section{Conclusions}

Our study provides novel evidence for a substantial T-type channel functional down-regulation induced by the TRPV1 
agonist capsaicin in rat DRG neurons and highlights the important role of intracellular $\mathrm{Ca}^{2+}$ in the negative modulation of T-type and HVA channels in primary sensory neurons. In particular, reducing the density of functional Ttype channels will elevate the threshold of action potential firing in hyperalgesic sensory neurons, attenuating the pain sensation of near threshold stimuli. This effect, thus may explain the dual action of capsaicin, which is both a pronociceptive stimulator and a potential analgesic compound. This novel information sheds further light into the molecular mechanisms underlying the analgesic actions of capsaicin and its analogues. Both TRPV1 antagonists and TRPV1 agonists are in clinical development for the treatment of various forms of acute and chronic pain. A better understanding of their mechanism of action will hopefully translate in more effective and tailored therapies.

Acknowledgments This work was supported by the MIUR (PRIN 2007SYRBBH_001) and the NIS (grant of Compagnia di SanPaolo).

\section{References}

1. Altier C, Zamponi GW (2004) Targeting $\mathrm{Ca}^{2+}$ channels to treat pain: T-type versus N-type. Trends Pharmacol Sci 25:465-470

2. Anderson D, Mehaffey WH, Iftinca M, Rehak R, Engbers JDT, Hameed S, Zamponi GW, Turner RW (2010) Regulation of neuronal activity by Cav3-Kv4 channel signaling complexes. Nat Neurosci 13:333-337

3. Backonja M, Wallace MS, Blonsky ER, Cutler BJ, Malan P Jr, Rauck R, Tobias J (2008) NGX-4010, a high-concentration capsaicin patch, for the treatment of postherpetic neuralgia: a randomised, double-blind study. Lancet Neurol 7:1106-1112

4. Bleakman D, Brorson JR, Miller RJ (1990) The effect of capsaicin on voltage-gated calcium currents and calcium signals in cultured dorsal root ganglion cells. Br J Pharmacol 101:423-431

5. Bourinet E, Alloui A, Monteil A, Barrère CB, Poirot O, Pages A, McRory J, Snutch TP, Eschalier A, Nargeot J (2005) Silencing of the $\mathrm{Ca}_{\mathrm{V}} 3.2$ T-type calcium channel gene in sensory neurons demonstrates its major role in nociception. EMBO J 24:315-324

6. Carabelli V, Marcantoni A, Comunanza V, de Luca A, Díaz J, Borges R, Carbone E (2007) Chronic hypoxia up-regulates $\alpha_{1 \mathrm{H}} \mathrm{T}$ type channels and low-threshold catecholamine secretion in rat chromaffin cells. J Physiol 584:149-165

7. Carbone E, Lux HD (1984) A low voltage-activated, fully inactivating $\mathrm{Ca}$ channel in vertebrate sensory neurons. Nature 310:501-502

8. Carbone E, Lux HD (1984) A low voltage-activated calcium conductance in embryonic chick sensory neurons. Biophys $\mathrm{J}$ 46:413-418

9. Carbone E, Lux HD (1987) Kinetics and selectivity of a lowvoltage activated calcium current in chick and rat sensory neurones. J Physiol 386:547-570

10. Carbone E, Marcantoni A, Giancippoli A, Guido D, Carabelli V (2006) T-type channels-secretion coupling: evidence for a fast low-threshold exocytosis. Pflugers Arch 453:373-383

11. Caterina MJ, Julius D (1999) Sense and specificity: a molecular identity for nociceptors. Curr Opin Neurobiol 9:525-530

12. Caterina MJ, Julius D (2001) The vanilloid receptor: a molecular gateway to the pain pathway. Annu Rev Neurosci 24:487-517
13. Caterina MJ, Schumacher MA, Tominaga M, Rosen TA, Levine JD, Julius D (1997) The capsaicin receptor: a heat-activated ion channel in the pain pathway. Nature 389:816-824

14. Caterina MJ, Leffler A, Malmberg AB, Martin WJ, Trafton J, Petersen-Zeitz KR, Koltzenburg M, Basbaum AI, Julius D (2000) Impaired nociception and pain sensation in mice lacking the capsaicin receptor. Science 288:306-313

15. Chung MK, Güler AD, Caterina MJ (2008) TRPV1 shows dynamic ionic selectivity during agonist stimulation. Nat Neurosci 11:555-564

16. Coste B, Crest M, Delmas P (2007) Pharmacological dissection and distribution of NaN/Nav1.9, T-type $\mathrm{Ca}^{2+}$ currents, and mechanically activated cation currents in different populations of DRG neurons. J Gen Physiol 129:57-77

17. Cribbs LL, Lee JH, Yang J, Satin J, Zhang Y, Daud A, Barclay J, Williamson MP, Fox M, Rees M, Perez-Reyes E (1998) Cloning and characterization of $\alpha 1 \mathrm{H}$ from human heart, a member of the TType $\mathrm{Ca}^{2+}$ channel gene family. Circ Res 83:103-109

18. Evans AR, Nicol GD, Vasko MR (1996) Differential regulation of evoked peptide release by voltage-sensitive calcium channels in rat sensory neurons. Brain Res 712:265-273

19. Fakata KL, Swanson SA, Vorce RL, Stemmer PM (1998) Pyrethroid insecticides as phosphatase inhibitors. Biochem Pharmacol 55:2017-2022

20. Fedulova SA, Kostyuk PG, Veselovsky NS (1985) Two types of calcium channels in the somatic membrane of new-born rat dorsal root ganglion neurones. J Physiol 359:431-446

21. Frolenkov GI, Mammano F, Belyantseva IA, Coling D, Kachar B (2000) Two distinct $\mathrm{Ca}^{2+}$-dependent signaling pathways regulate the motor output of cochlear outer hair cells. J Neurosci 20:5940-5948

22. Gold MS, Dastmalchi S, Levine JD (1996) Co-expression of nociceptor properties in dorsal root ganglion neurons from the adult rat in vitro. Neuroscience 71:265-275

23. Gunthorpe MJ, Benham CD, Randall A, Davis JB (2002) The diversity in the vanilloid (TRPV) receptor family of ion channels. Trends Pharmacol Sci 23:183-191

24. Guo A, Vulchanova L, Wang J, Li X, Elde R (1999) Immunocytochemical localization of the vanilloid receptor 1 (VR1): relationship to neuropeptides, the $\mathrm{P} 2 \mathrm{X} 3$ purinoceptor and IB4 binding sites. Eur J Neurosci 11:946-958

25. Harper AA, Lawson SN (1985) Conduction velocity is related to morphological cell type in rat dorsal root ganglion neurones. J Physiol 359:31-46

26. Helliwell RJ, McLatchie LM, Clarke M, Winter J, Bevan S, McIntyre P (1998) Capsaicin sensitivity is associated with the expression of the vanilloid (capsaicin) receptor (VR1) mRNA in adult rat sensory ganglia. Neurosci Lett 250:177-180

27. Huang Z, Lujan R, Kadurin I, Uebele VN, Renger JJ, Dolphin AC, Shah MM (2011) Presynaptic HCN1 channels regulate $\mathrm{Ca}_{\mathrm{V}} 3.2$ activity and neurotransmission at select cortical synapses. Nat Neurosci 14:478-486

28. Jagodic MMJ, Pathirathna S, Nelson MT, Mancuso S, Joksovic PM, Rosenberg ER, Bayliss DA, Jevtovic-Todorovic V, Todorovic SM (2007) Cell-specific alterations of T-type calcium current in painful diabetic neuropathy enhance excitability of sensory neurons. J Neurosci 27:3305-3316

29. Jevtovic-Todorovic V, Todorovic SM (2006) The role of peripheral T-type calcium channels in pain transmission. Cell Calcium 40:197-203

30. Jun K, Piedras-Rentería ES, Smith SM, Wheeler DB, Lee SB, Lee TG, Chin H, Adams ME, Scheller RH, Tsien RW, Shin HS (1999) Ablation of $\mathrm{P} / \mathrm{Q}$-type $\mathrm{Ca}^{2+}$ channel currents, altered synaptic transmission, and progressive ataxia in mice lacking the $\alpha_{1 \mathrm{~A}}$ subunit. Proc Natl Acad Sci USA 96:15245-15250

31. Kim C, Jun K, Lee T, Kim SS, McEnery MW, Chin H, Kim HL, Park JM, Kim DK, Jung SJ, Kim J, Shin HS (2001) Altered 
nociceptive response in mice deficient in the $\alpha_{1 \mathrm{~B}}$ subunit of the voltage-dependent calcium channel. Mol Cell Neurosci 18:235245

32. Kohane DS, Lu NT, Gökgöl-Kline AC, Shubina M, Kuang Y, Hall S, Strichartz GR, Berde CB (2000) The local anesthetic properties and toxicity of saxitonin homologues for rat sciatic nerve block in vivo. Reg Anesth Pain Med 25:52-59

33. Koplas PA, Rosenberg RL, Gerry S, Oxford GS (1997) The role of calcium in the desensitization of capsaicin responses in rat dorsal root ganglion neurons. J Neurosci 17:3525-3537

34. Kozlov AS, McKenna F, Lee JH, Cribbs LL, Perez-Reyes E, Feltz A, Lambert RC (1999) Distinct kinetics of cloned T-type $\mathrm{Ca}^{2+}$ channels lead to differential $\mathrm{Ca}^{2+}$ entry and frequency-dependence during mock action potentials. Eur J Neurosci 11:4149-4158

35. LaMotte RH, Lundberg LE, Torebjörk HE (1992) Pain, hyperalgesia and activity in nociceptive $\mathrm{C}$ units in humans after intradermal injection of capsaicin. J Physiol 448:749-764

36. Lee JH, Gomora JC, Cribbs LL, Perez-Reyes E (1999) Nickel block of three cloned T-Type calcium channels: low concentrations selectively block alpha1H. Biophys J 77:3034-3042

37. Lee MH, Yeon KY, Park CK, Li HY, Fang Z, Kim MS, Choi SY, Lee SJ, Lee S, Park K, Lee JH, Kim JS, Oh SB (2005) Eugenol inhibits calcium currents in dental afferent neurons. J Dent Res 84:848-851

38. Liu L, Simon SA (1996) Capsaicin-induced currents with distinct desensitization and $\mathrm{Ca}^{2+}$ dependence in rat trigeminal ganglion cells. J Neurophysiol 75:1503-1514

39. Liu L, Oortgiesen M, Li L, Simon SA (2001) Capsaicin inhibits activation of voltage-gated sodium currents in capsaicin-sensitive trigeminal ganglion neurons. J Neurophysiol 85:745-758

40. Marcantoni A, Vandael DH, Mahapatra S, Carabelli V, SinneggerBrauns MJ, Striessnig J, Carbone E (2010) Loss of $\mathrm{Ca}_{\mathrm{V}} 1.3$ channels reveals the critical role of L-type and BK channel coupling in pacemaking mouse adrenal chromaffin cells. J Neurosci 30:491-504

41. McRory JE, Santi CM, Hamming KSC, Mezeyova J, Sutton KG, Bailliei DL, Stea A, Snutch TP (2001) Molecular and functional characterization of a family of rat brain T-type calcium channels. J Biol Chem 276:3999-4011

42. Nagy I, Sántha P, Jancsó G, Urbán L (2004) The role of the vanilloid (capsaicin) receptor (TRPV1) in physiology and pathology. Eur J Pharmacol 500:351-369

43. Nelson MT, Joksovic PM, Perez-Reyes E, Todorovic SM (2005) The endogenous redox agent L-cysteine induces T-type $\mathrm{Ca}^{2+}$ channel-dependent sensitization of a novel subpopulation of rat peripheral nociceptors. J Neurosci 25:8766-8775

44. Novara M, Baldelli P, Cavallari D, Carabelli V, Giancippoli A, Carbone E (2004) Exposure to cAMP and $\beta$-adrenergic stimulation recruits $\mathrm{Ca}_{\mathrm{V}} 3$ T-type channels in rat chromaffin cells through Epac cAMP-receptor proteins. J Physiol 558:433-449

45. Perez-Reyes E (2003) Molecular physiology of low-voltageactivated T-type calcium channels. Physiol Rev 83:117-161

46. Perez-Reyes E, Cribbs LL, Daud A, Lacerda AE, Barclay J, Williamson MP, Fox M, Rees M, Lee JH (1998) Molecular characterization of a neuronal low voltage-activated T-type calcium channel. Nature 391:896-900

47. Petersen M, LaMotte RH (1991) Relationships between capsaicin sensitivity of mammalian sensory neurons, cell size and type of voltage gated Ca-currents. Brain Res 561:20-26

48. Petruska C, Napaporn J, Johnson RD, Coope BY (2002) Chemical responsiveness and histochemical phenotype of electrophysiologically classified cells of the adult rat dorsal root ganglion. Neuroscience 115:15-30

49. Prakriya M, Lingle CJ (2000) Activation of BK channels in rat chromaffin cells requires summation of $\mathrm{Ca}^{2+}$ influx from multiple $\mathrm{Ca}^{2+}$ channels. J Neurophysiol 84:1123-1135
50. Randall AD, Tsien RW (1997) Contrasting biophysical and pharmacological properties of T-type and R-type calcium channels. Neuropharmacology 36:879-893

51. Rola R, Szulczyk PJ, Witkowski G (2003) Voltage-dependent $\mathrm{Ca}^{2+}$ currents in rat cardiac dorsal root ganglion neurons. Brain Res 961:171-178

52. Sawynok J (2003) Topical and peripherally acting analgesic. Pharmacol Rev 55:1-20

53. Schroeder JE, Fischbach PS, McCleskey EW (1990) T-type calcium channels: heterogeneous expression in rat sensory neurons and selective modulation by phorbol esters. J Neurosci 10:947-951

54. Scroggs RS, Fox AP (1992) Calcium current variation between acutely isolated adult rat dorsal root ganglion neurons of different size. J Physiol 445:639-658

55. Shin JB, Martinez-Salgado C, Heppenstall PA, Lewin GR (2003) A T-type calcium channel required for normal function of a mammalian mechanoceptor. Nat Neurosci 6:724-730

56. Su X, Wachtel RE, Gebhart GF (1999) Capsaicin sensitivity and voltage-gated sodium currents in colon sensory neurons from rat dorsal root ganglia. Am J Physiol 277:1180-1188

57. Szallasi A, Blumberg PM (1999) Vanilloid (Capsaicin) receptors and mechanisms. Pharmacol Rev 51:159-211

58. Szolcsányi J, Pintér E, Helyes Z, Oroszi G, Németh J (1998) Systemic anti-inflammatory effect induced by counter-irritation through a local release of somatostatin from nociceptors. Br J Pharmacol 125:916-922

59. Talley EM, Cribbs LL, Lee JH, Daud A, Perez-Reyes E, Bayliss DA (1999) Differential distribution of three members of a gene family encoding low voltage-activated (T-type) calcium channels. J Neurosci 19:1895-1911

60. Todorovic SM, Lingle CJ (1998) Pharmacological properties of Ttype $\mathrm{Ca}^{2+}$ current in adult rat sensory neurons: effects of anticonvulsant and anesthetic agents. J Neurophysiol 79:240-252

61. Todorovic SM, Meyenburg A, Jevtovic-Todorovic V (2002) Mechanical and thermal antinociception in rats following systemic administration of mibefradil, a T-type calcium channel blocker. Brain Res 951:336-340

62. Tominaga M, Caterina MJ, Malmberg AB, Rosen TA, Gilbert H, Skinner K, Raumann BE, Basbaum AI, Julius D (1998) The cloned capsaicin receptor integrates multiple pain-producing stimuli. Neuron 21:531-543

63. Tsien RY (1980) New calcium indicators and buffers with high selectivity against magnesium and protons: design, synthesis, and properties of prototype structures. Biochemistry 19:2396-2404

64. Tsien RW, Clozel JP, Nargeot J (1998) Low voltage-activated Ttype calcium channels. Adis International Limited, Chester

65. Vellani V, Mapplebeck S, Moriondo A, Davis JB, McNaughton PA (2001) Protein kinase $C$ activation potentiates gating of the vanilloid receptor VR1 by capsaicin, protons, heat and anandamide. J Physiol 534:813-825

66. White G, Lovinger DM, Weight FF (1989) Transient lowthreshold $\mathrm{Ca}^{2+}$ current triggers burst firing through an afterdepolarizing potential in an adult mammalian neuron. Proc Natl Acad Sci USA 86:6802-6806

67. Wu ZZ, Chen SR, Pan HL (2005) Transient receptor potential vanilloid type 1 activation down-regulates voltage-gated calcium channels through calcium-dependent calcineurin in sensory neurons. J Biol Chem 18:18142-18151

68. Wu ZZ, Chen SR, Pan HL (2006) Signaling mechanisms of downregulation of voltage-activated $\mathrm{Ca}^{2+}$ channels by transient receptor potential vanilloid type 1 stimulation with olvanil in primary sensory neurons. Neuroscience 141:407-419

69. Yang K, Kumamoto E, Furue H, Li YQ, Yoshimura M (1999) Action of capsaicin on dorsal root-evoked synaptic transmission 
to substantia gelatinosa neurons in adult rat spinal cord slices. Brain Res 830:268-273

70. Yang BH, Piao ZG, Kim YB, Lee CH, Lee JK, Park K, Kim JS, Oh SB (2003) Activation of vanilloid receptor 1 (VR1) by eugenol. J Dent Res 82:781-785

71. Yunker AMR, McEnery MW (2003) Low-voltage-activated ("Ttype") calcium channels in review. J Bioenerg Biomembr 35:577-579
72. Zamponi GW, Lewis RJ, Todorovic SM, Arneric SP, Snutch TP (2009) Role of voltage-gated calcium channels in ascending pain pathways. Brain Res Rev 60:84-89

73. Zhang X-F, Han P, Neelands TR, McGaraughty S, Honore P, Surowy CS, Zhang D (2011) Coexpression and activation of TRPV1 suppress the activity of the KCNQ2/3 channel. J Gen Physiol. doi:10.1085/jgp.201110618 